\title{
Hill country goat farming in perspective
}

\section{G.J. Batten}

Caprinex, P.O. Box 102,

Brightwater, Nelson

ABSTRACT Commerical fibre-goat farming has grown in the last 10 years from nil to 1.25 million goats on 9437 farms producing $\$ 13.7 \mathrm{~m}$ fibre income. Development has come through having potentially highly productive goats, mains-powered electric fences to control them, investment capital from outside the industry, and pioneer dedication that also produced an integrated fibre handling and marketing operation, all managed by adaptable and innovative hill country farmers. Goat husbandry and management, including breeding, fibre handling, stocking rates, pasture and weed feeding, need a different attitude and philosophy to those needed for sheep and cattle traditionally farmed on hill country. Fast industry growth has outstripped relevant information and the farm management profession has assisted farmers to develop techniques and systems. Research is now producing some reasons for applied practices. Numbers of farmed goats are expected to continue to increase. Each hill country farm can have a profitable doe and wether flock integrated into sheep and cattle management.

Keywords pasture, mohair, cashmere, cashgora, weed control

\section{INTRODUCTION}

Ten years from the start of new wave commercial goat farming is an appropriate time to put it into perspective in New Zealand hill country. We can make reasoned and reasonable statements about where the industry is now and how goats are being farmed on hill country, how it got to this point, and about prospects for the next 10 years.

Commercial goat farming is now permanently established on hill country with goats producing income from cashmere, cashgora, mohair, meat and skins, reducing costs by controlling scrub and pasture weeds, and by complementing sheep and cattle grazing. Expansion has been at near maximum biological rate after allowing for feral capture, with over 2 million goats expected on farms after spring 1989 kidding and expected fibre income in 1989 at over $\$ 20.0 \mathrm{~m}$ compared with 10000 goats in 1979, producing $\$ 1$.Om (Department of Statistics). Tables I and 2 show the most recently available statistics.

\section{WHERE IS THE GOAT INDUSTRY NOW?}

\section{Breeds and breeding}

The down fibres (cashmere and cashgora) plus mohair are the focus of hill country goat farming and are fundamental to future developments. Ten years ago farmers started using Angora bucks to upgrade bush does which were subsequently found to be producing variable cashmere and have since been farmed for it. Some of the crossbred fibre has been bought by processors as cashgora. At least two of these three fibre types are produced on most farms.

Angoras developed from a very narrow genetic base modified by upgraded bush goats and variable quality Australian imports. They now produce lightweight fleeces by world standards of generally fine, kempy mohair for a market that pays a premium for tine, kemp free mohair. Cashmere fleece price reflects weight and fineness now that colour discounts have practically disappeared and down:total fleece yields have reached market acceptable levels. Cashgora is produced by diverse animals at the strong end of cashmere flocks, fine end of crossbred Angora flocks and from some animals specifically bred to produce it. All fibre flocks show a wide range in fibre type, production and quality.

Farmers decide the type of goats to suit them and their farms using criteria of income, husbandry costs, labour and capital inputs, product markets and personal satisfaction. They are able to capitalise on the vast genetic potential of the quality range, high heritabilities of fibre production (Yalcin 1982; Restall \& Pattie 1988) and high goat reproductive rate to make the very rapid progress already demonstrated by recent pioneers.

Most hill country farmers appreciate the need for objective measurements of the few significant profit factors of fleece weight, kemp/yield, and mean fibre diameter. They also understand genetics. The relative unimportance of nutrition on cashmere production (McCall \& Fitzgerald 1987) concentrates even more emphasis on breeding policies, decisions and actions.

\section{Fibre harvesting}

Goat fibre is a completely different product to wool. High values for small quantities justify very careful shearing and handling of the clip. Goat losses after shearing have been minimised by an understanding of goat physiology. Farmers often shear their own 
goats over several weeks rather than adopt the traditional sheep approach of minimising time allocated to shearing.

\section{Stocking rates}

Some very large flocks of thousands of goats are, being farmed but many flocks are run on part of a farm only. Yet goat stock density in the present state of husbandry and management sophistication is often a key factor to profitability and success.

Low goat stocking density allows optimal diet selection (McCall \& Fitzgerald 1987), reduced pasture bruising and health and behaviour problems because of reduced animal stress. It also enhances goats' complementary role when eating unwanted sheep and cattle feed and by promoting clover component in pastures (Radcliffe \& Moorhouse 1988). Many farms have added $10 \%$ of their total stock units as goats without depressing sheep and cattle production. However, more than $50 \%$ of total stocking rate in goats magnifies the problems in farming them through increased animal ill health and stress and pasture changes.

It is difficult to make stocking rate recommendations to farmers because of goat liveweight variations, even though dry matter requirements relate directly to body weight. Farmers are not used to assessing goat feed that includes scrub and thistles and parts of pasture plants not normally eaten by sheep. Farms have different goat feed profiles.

With such complications, a starting point of 1 goat per ha allows farmers to develop feed management knowledge according to the size and type of their goats and their feed supplies.

\section{Pasture feeding}

Sheep and cattle pastoral feeding is not particularly applicable to goats that are browsers eating pasture with shallower bites. They are opportunists selecting, from what is available, different plants or different parts of plants with different major and minor elements. Goats are both selective and adaptive over the short term to quantity and quality.

Goats are constantly moving in mobs that bruise pasture plants, especially improved species, with consequent rejection even with a large herbage mass. The feeding method preferred is therefore to increase feeding area and reduce stocking density, or reduce time on an area. This means either lax set stocking or frequent mob rotation, but at low stocking rates the difference in the method is not important.

Pasture feed management has been hindered by farmers' lack of knowledge about their goats and their requirements dictated by size, age, milk production and fibre growth

However, goats produce well on hill country pastures and do eat white clover. Minimum pasture levels are greater than for sheep (McCall \& Fitzgerald 1987) but depend on stock density, overall farm stocking rate, feeding system, and feed type and species. One quide to farmers has been to treat goats like cattle for pasture heights.

However, laxly grazed goats alone do not maintain pasture species in a highly productive vegetative state, and mixed stocking is necessary.

\section{Weed feeding}

Many farmers feed their goats directly or indirectly on weeds and the consequent nutritional stress is accepted by hill country farmers given the problems and limits of alternative weed control methods. Pasture weeds such as thistles and rushes, and scrub weeds such as blackberry, manuka and gorse can be controlled and eliminated by goats. The method used depends on weed density and species, stage of growth, number and type of goats available, ability to confine goats and degree of weed control required (Batten 1979).

Continual weed nibbling over a long period is often better than traditional mob stocking methods. It may take 3-4 years to markedly reduce thistles through killing biennial plants, reducing seeding, and enhancing pasture competition. Minor plant species suffer first during the goat's search for diet variety.

There is an established place for fibre-producing wethers, as shown in Table 1. Stronger and more aggressive down-producing wether goats handle stress better than does, can adjust bodyweights to fluctuating feed supplies without affecting production, have low capital and husbandry costs, and can produce substantial fibre income.

\section{Husbandry}

Commercial goat husbandry has been hindered by lack of knowledge. Goat health is still surrounded by myth and magic but the critical areas of foot

Table 1 Goat Numbers (thousands) excluding dairy goats as at 30 June $1988 \dagger$

\begin{tabular}{|c|c|c|c|c|c|c|c|c|c|c|c|c|c|}
\hline & \multirow[t]{2}{*}{$\begin{array}{l}\text { Goat } \\
\text { farms }\end{array}$} & \multicolumn{6}{|c|}{ Breeding does } & \multirow[t]{2}{*}{$\begin{array}{c}\text { Other } \\
\text { does }\end{array}$} & \multicolumn{4}{|c|}{ Male goats } & \multirow[t]{2}{*}{ Totals } \\
\hline & & Angora & Cashgora & cashmere & Other & Av. flock & $\operatorname{Kid} \%$ & & Angora & shgora & imere & Other & \\
\hline North Island & 6314 & 90.3 & 114.0 & 124.3 & 122.9 & 71.2 & 96 & 141.8 & 70.3 & 117.6 & 51.9 & 89.5 & 922.6 \\
\hline South Island & 3123 & 42.8 & 36.8 & 53.6 & 36.7 & 54.4 & 108 & 53.2 & 35.6 & 38.9 & 21.1 & 28.3 & 347.0 \\
\hline New Zealand & 9437 & 133.1 & 150.8 & 177.9 & 159.6 & 65.8 & 100 & 195.0 & 105.9 & 156.5 & 73.0 & 1178 & 1269.6 \\
\hline
\end{tabular}

$\uparrow$ Source: Department of Statistics 
problems and internal parasites have been identified.

Goats travel over longer distances each day than sheep and cattle, and sound feet are critical. There has been progress in eliminating scald and footrot through culling and breeding resistance. Ivermectin is the preferred anthelmintic and integrated pasture management a preferred technique for internal parasite control.

Table 2 Goat fibre production $1988 \dagger$

\begin{tabular}{|c|c|c|c|c|c|c|c|}
\hline & $\begin{array}{r}\text { Tonnes } \\
\text { tleece }\end{array}$ & $\begin{array}{r}\text { Tonnes } \\
\text { down } \\
\end{array}$ & $\begin{array}{l}\% \text { w } \\
\text { from }\end{array}$ & $\begin{array}{l}\text { 1ncrease } \\
\mathrm{n} \quad 1987 \text { ( }\end{array}$ & $\begin{array}{l}\text { Value } \\
\$ \mathrm{ml}\end{array}$ & $\begin{array}{r}\% \text { of } \\
\text { total } \$\end{array}$ & $\begin{array}{l}\% \text { value increase } \\
\text { from } 1987\end{array}$ \\
\hline $\begin{array}{l}\text { Mohair } \\
\text { Cashmere } \\
\text { Cashgora }\end{array}$ & $\begin{array}{l}430 \\
100 \\
264\end{array}$ & $\begin{array}{r}30 \\
132\end{array}$ & & $\begin{array}{l}53 \\
76 \\
81\end{array}$ & $\begin{array}{l}2.27 \\
3.82 \\
1.62\end{array}$ & $\begin{array}{l}16.5 \\
27.9 \\
55.6\end{array}$ & $\begin{array}{r}\mid \\
133 \\
94\end{array}$ \\
\hline Totals & 795 & & & & 13.7 & & \\
\hline
\end{tabular}

† Source: NZ Mohair Cashmere Warehouse Co. Ltd

Better husbandry and handling methods and techniques come from better understanding of the goat itself. Sheep and cattle equipment and facilities have been adapted, but farmers are also learning to exploit the goat's attributes of intelligence, agility and behaviour to facilitate their management, for example by shearing them standing up.

\section{Meat}

Farmers have been confused by problems of unprofitable prices and slaughter difficulties compounded by the problems of the whole meat industry. A clearer perspective comes from accepting that goats are fibre producers and weed control is the byproduct.

\section{Financial returns}

Gross margin analysis that assumes a common base cost for feed, labour and sometimes capital cannot be used to evaluate goat returns with the wide variation in their size, production and feeding costs, and different ratios of capital and labour inputs compared with sheep and cattle. Gross and net income figures per goat or per ha can be misleading because of these variations. Nevertheless, more than $10 \%$ of farmers are finding that the financial returns from goat farming are rewarding in their terms.

\section{HOW HAS THE INDUSTRY GOT THERE?}

Goats, sheep and cattle are now all seen as hill country farm animals. The ratios of each depend on farm and farmer. There have been six major steps along this 10 year path.

Firstly, goats are relatively adaptive, with an inherent capacity for dramatic production improvement. Secondly, mains-powered electric fencing enabled farmed goats to be controlled for the first time. Thirdly, outside investment capital has fostered feral goat capture, embryo transfer from superior goats and entrepreneural action from farmers with insufficient of their own resources.

The fourth step was the dedication of some recent pioneers who saw a role for goats and persevered to build an industry. This produced the fifth step of the voluntary, producercontrolled fibre handling and marketing structure that has been a framework for sound industry growth with vertical integration and lateral diversification.

Finally, adaptable, ingenious and skilful farmers have taken an unfamiliar animal and in 10 years turned it into a farmed animal in its own right on New Zealand hill country. In this, farmers have been assisted by the farm management profession who have helped farmers overcome problems of lack of information, education and training over the whole range of goat breeding, feeding, husbandry, management and marketing.

\section{The information flow}

Changes in research funding policies magnified problems for this new industry, which was required to help fund its own research before it could generate the resources to do so. Farmers have developed goat farming with as yet many unanswered questions and little relevant information from researchers who are now starting to explain reasons for accepted practices.

A major impediment to information flow within the industry has been variation between goats, their products, markets for those products, soils, climate, stocking densities and management. Often these differences are still not yet fully realised by some research workers, farmers and their advisers. The information flow was also hindered by 'factual' myths of earlier years and extrapolating small farm and flock experiences to commercial goat farming.

Rapid growth of this industry with little research data has highlighted the interpretive role of farm management consultants. They created a viable information base from repeated observations of commercial operations over space, time and a range of conditions related to known facts.

\section{WHERE WILL THE GOAT INDUSTRY GO?}

Goats make economic and practical sense now and have a tremendous capacity for improvement. Barriers to progress are now largely attitudinal rather than practical and in production rather than marketing. However, innovation has been one characteristic of goat farmers and is a key to more goats on more farms.

Some guidelines for farmers are:

- adopting a fine wool, not crossbred philosophy as a model for farming goats - not using sheep solutions for goat problems 
- goat proofing the boundary fence and spreading out the goats

- starting with a small, good quality flock and learning about goat farming

observing goats, discussing and sharing the knowledge with objective people

- accepting the differences between goats, deciding which type suits the farm and farmer, and focusing on improving goat production through breeding

- keeping management simple, and concentrating on the basics of good shearing and feeding management

It will be relatively easy to double the present cashmere/cashgora flock, and their fibre exports to reach $\$ 30 \mathrm{~m}$ annually without diminishing existing sheep and cattle production.

I believe that a typical hill country farm in 1999 can have a 100 doe flock with rapidly improving fleece production, producing its own replacements, and a 200 mixed age wether flock. Young animals will be grazed with calves until a year old, and does will be spread out on easier paddocks, controlling pasture weeds and seedheads. Wethers will keep scrub weeds under control. The farm will also have $\$ 5000$ of direct income from fibre sales with very little extra work and capital outlay.

\section{REFERENCES}

Batten, G.J. 1979. Controlling scrub weeds with goats. Proceedings of the NZ Weed and Pest Control Conference 32: 292-296.

Department of Statistics. Agricultural and Pastoral Statistics. Government Printer (various issues).

McCall, D.G.; Fitzgerald, J.M. 1987. Growth and fleece responses of Cashmere goats to late pregnancy and lactation feeding at pasture. Proceedings 2nd International Cashmere Conference, Lincoln College 125-136.

Radcliffe, J.E.; Moorhouse, S.R. 1988. Integrating goats with other livestock improves performance of paired animal. Premier Fibre News, O ctober 1988: 16-18.

Restall, B.J.; Pattie, W.A. 1988. The inhertiance of production characteristics in goats. Australian Association of Animal Breeding and Genetics.

Yalcin B.C. 1982. Angora goat breeding. Proceedings of the Third International Conference on $\mathrm{G}$ oat Production and Disease: 269-278. 